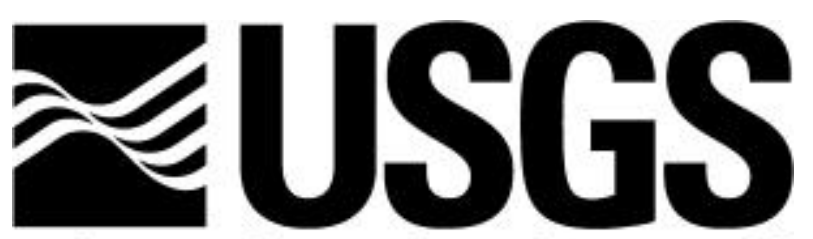

science for a changing world

\title{
A TEST OF A MECHANICAL MULTI-IMPACT SHEAR-WAVE SEISMIC SOURCE
}

by David M. Worley, Jack K. Odum, Robert A. Williams, and William J. Stephenson

Open-File Report 01-0440

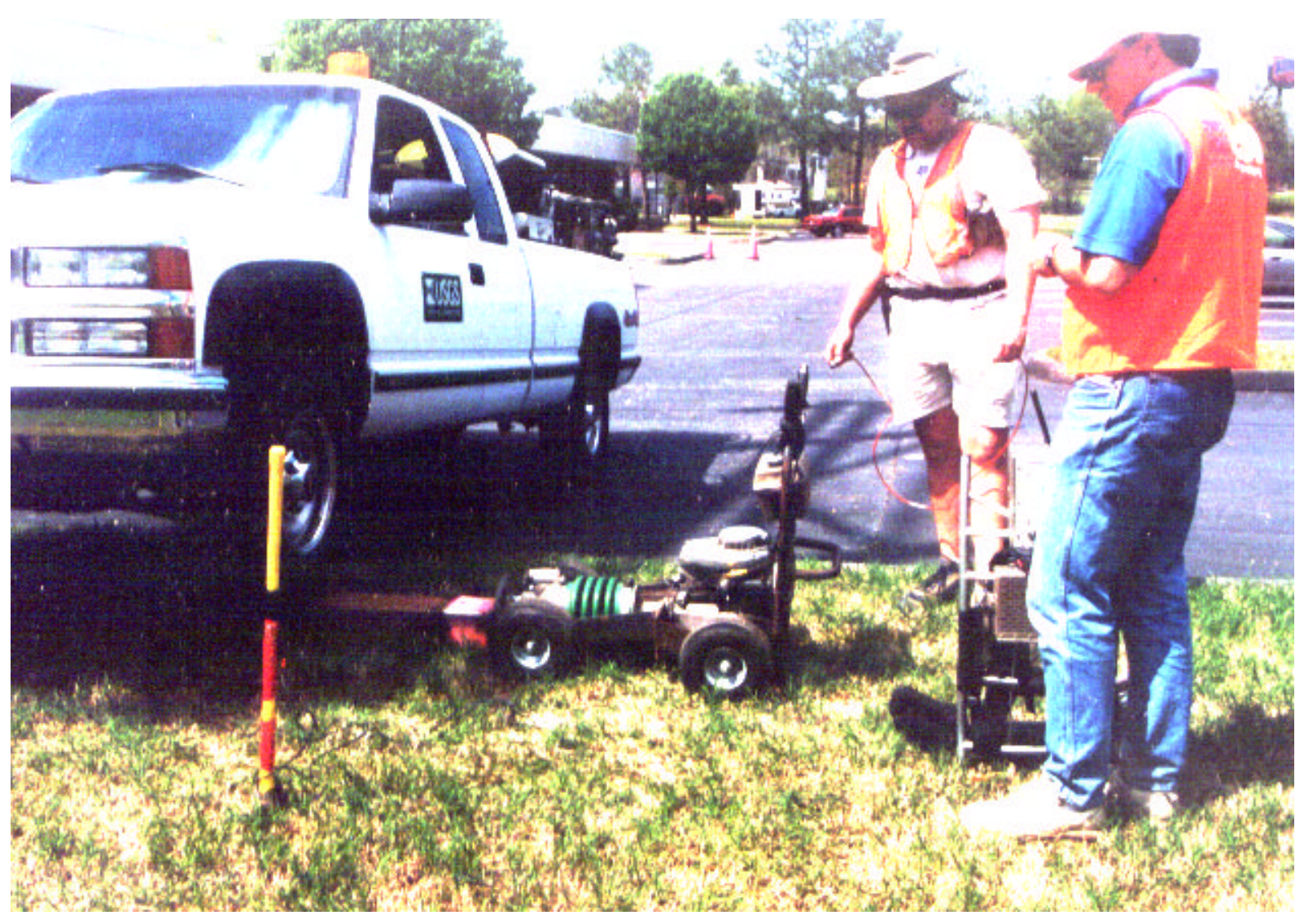

This report is preliminary and has not been reviewed for conformity with U.S. Geological Survey editorial standards and stratigraphic nomenclature. Any use of trade names is for descriptive purposes only and does not imply endorsement by the USGS.

\section{U.S. DEPARTMENT OF THE INTERIOR}

\section{U.S. Geological Survey}

Golden, Colorado 


\title{
A TEST OF A MECHANICAL MULTI-IMPACT SHEAR-WAVE SEISMIC SOURCE
}

\author{
By David M. Worley, Jack K. Odum, Robert A. Williams, William J. Stephenson
}

\begin{abstract}
We modified two gasoline-engine-powered earth tampers, commonly used as compressional-(P) wave seismic energy sources for shallow reflection studies, for use as shear(S)-wave energy sources. This new configuration, termed "Hacker" (horizontal Wacker ${ }^{\circledR}$ ), is evaluated as an alternative to the manual sledgehammer typically used in conjunction with a large timber held down by the front wheels of a vehicle. The Hacker maximizes the use of existing equipment by a quick changeover of bolt-on accessories as opposed to the handling of a separate source, and is intended to improve the depth of penetration of S-wave data by stacking hundreds of impacts over a two to three minute period.

Records were made with a variety of configurations involving up to two Hackers simultaneously then compared to a reference record made with a sledgehammer. Preliminary results indicate moderate success by the higher amplitude S-waves recorded with the Hacker as compared to the hammer method. False triggers generated by the backswing of the Hacker add unwanted noise and we are currently working to modify the device to eliminate this effect. Correlation noise caused by insufficient randomness of the Hacker impact sequence is also a significant noise problem that we hope to reduce by improving the coupling of the Hacker to the timber so that the operator has more control over the impact sequence.
\end{abstract}

\section{INTRODUCTION}

Accurate measurement of shallow S-wave velocity (Vs) in sedimentary basins is crucial for earthquake ground-motion models. However, collecting such data in an urban environment normally involves restrictions in operations imposed by the local governments, including but not limited to: (a) very restricted use of explosives, (b) no large impacts which might damage property, and (c) adherence to noise level ordinances. Urban data collection is further hampered by the ambient noise of it's own environment, which requires the use of one or more noise cancellation techniques. In an effort to devise an inexpensive and rapid method of determining Vs in the upper $200 \mathrm{~m}$ that complies with the imposed restrictions, improves the signal-to-noise ratio of S-wave data used for research and earthquake engineering, and increases depth of penetration, we constructed a 
new non-invasive S-wave seismic source by modifying a pair of Wackers ${ }^{\circledR}$ for horizontal operation. Records were digitally recorded with a Geometrics StrataView engineering seismograph using a method with similarities to both vibroseis recording and the Mini-Sosie method (Barbier, 1983).

A variety of non-explosive surface sources are currently used to generate $\mathrm{SH}$ waves. These include a horizontal timber or similar object, pressed against the ground surface and struck manually at the ends with a hammer. This method was introduced by Kobayashi (1959) and is uncomplicated, inexpensive, and reasonably reliable. It is limited in effectiveness by a lesser depth of penetration than other methods, and the considerable human physical effort required. In a similar method, the manually-operated hammer in the first method is replaced by a falling hammer hinged at an axis and striking the timber horizontally. The limitations of this alternative are noise restrictions, logistical constraints of size, and speed of operation. Typically, a physically larger source generates more energy that provides better imaging at depth, but larger sources may be restricted for the greater noise they produce or potential environmental damage, and are logistically more awkward to use due to their size and weight. Shear-wave vibrators using the vibroseis principle, in which a reaction mass is accelerated relative to a shaft fixed to a base plate by hydraulic forces are also popular. This method offers superior energy input and repeatability. The limitations to this method are that it is very expensive to purchase or lease and maintain, and it is often environmentally damaging. Other types of sources use a shuttle mass propelled by compressed air to impact an anvil fixed to the base plate (Meissner et al., 1985), or masses affixed to an air-actuated cylinder (Liu et al., 1988). The resulting traction exerted on the ground surface by the base plate generates the shear-waves. These devices provide excellent energy input and repeatability. Generally, a lifting device, such as a manual crane, must be used to move them. A large, gasoline-engine-powered air compressor is also required for operation. The limitations are the requirement for supporting equipment and difficulty in handling placement of the massive air hammer.

We believe the Hacker has the potential to solve, or ease, many of the limitations described above because it is a commonly available device (in vertically-oriented form from construction rental agencies), easy to operate, easily handled in small areas, provides more energy than manual methods by stacking hundreds of impacts, not excessively noisy, and not damaging to the environment or infrastructure. The purpose of this initial report on the Hacker is to summarize: 1) the progress made in successfully converting a Wacker ${ }^{\circledR}$ to a Hacker, 2) the success in generating an 
$\mathrm{S}$-wave seismic record that is comparable to a conventional sledgehammer/timber configuration, 3) the limitations and complications encountered in testing this new device that need to be resolved before the Hacker is fully proven as an improved S-wave source.

\section{Source Modifications: Creating a Hacker from a Wacker}

We modified two 68-Kg Wacker ${ }^{\circledR \ddagger}$ GVR-151Y gasoline-engine-driven mechanical tampers, each having a striking force of approximately $1360 \mathrm{Kg}$ in the vertical configuration, for horizontal operation by fitting each with a small steel frame bolted to the body of the tamper and affixed with four balloon tires (Figure 1). The footplate was replaced with a circular, flat steel plate. For both vertical and horizontal configurations, the factory throttle control was replaced with a motorcycle handgrip/throttle control to facilitate the requirement of frequent engine speed variation to produce the pseudo-random impact series. The end of the $15.24 \mathrm{~cm} \mathrm{X} 15.24 \mathrm{~cm} \mathrm{X} 304.8 \mathrm{~cm}$ fir timber was fitted with a steel end plate of sufficient width to permit the operation of two tampers side-by-side and reinforced with gussets (Figure 1). An impact-sensing device was attached to the base of each tamper to provide a reference pulse to the seismograph pilot signal channel (Figure 1). The data were correlated to these pulses (Figure 2). Records were made in a variety of configurations and compared to reference records made with sledgehammer impacts against a timber or steel cleat (designed by Hasbrouck, W. P., personal communication) (Figures 3). The sources were operated in a pseudo-random fashion, as used in the Mini-Sosie method, to reduce random noise by varying the rate and frequency of the source impacts. For this study the number of impacts from a single Hacker during 60-s recording was about 175. This method has been used successfully by the U.S. Geological Survey to acquire P-wave reflection data in a vertical impact configuration (e.g.:

Stephenson, et al., 1999).

\section{CONFIGURATION AND TESTS}

These tests were conducted on grass at the west end of the Ulysses Park softball field complex in Golden, Colorado. Scott (1972) indicates that the site lies on the Denver Formation, which can be up to 290-m thick, and consists of claystone, siltstone, friable sandstone, and conglomerate. To record the data we deployed a linear seismic receiver line of $60,4.5 \mathrm{~Hz}$ horizontal geophones using a receiver interval of $1.5 \mathrm{~m}$. The source timber was placed at the end of the receiver array and oriented perpendicular to the receiver line. The front of a pickup truck served as weight on the timber to improve seismic coupling to the ground and restrict movement of the timber (Fig. 1). 
Five-cm-long steel cleats on the bottom of the timber penetrated the sod and helped to minimize slippage of the timber. The steel S-wave cleat (Figure 3) was placed at the same location and weighted by one person. A $1 \mathrm{~ms}$ sample interval was selected. A $60 \mathrm{~Hz}$ notch filter was used due to the proximity of a power distribution line. A summary of the seismic source tests, corresponding to a specific record number, for the data described in this report is listed in Table 1.

\begin{tabular}{|l|l|l|}
$\begin{array}{l}\text { Table 1. Test file summary } \\
\text { Record } \\
\text { Number }\end{array}$ & $\begin{array}{l}\text { Source } \\
\text { Configuration }\end{array}$ & $\begin{array}{l}\text { Recording } \\
\text { Parameters }\end{array}$ \\
\hline 1002 & $\begin{array}{l}\text { Sledgehammer with } \\
\text { steel S-wave shoe }\end{array}$ & $\begin{array}{l}\text { 1 second record. } \\
\text { Stack of 4 hammer blows. }\end{array}$ \\
\hline 1004 & $\begin{array}{l}\text { Sledgehammer with } \\
\text { timber. }\end{array}$ & $\begin{array}{l}\text { 1 second record. } \\
\text { Stack of 4 hammer blows. }\end{array}$ \\
\hline 1005 & One Hacker & 64 s record, uncorrelated \\
\hline 1006 & One Hacker & $\begin{array}{l}\text { 1 second record consisting of } \\
\text { four 24 second records } \\
\text { correlated, then stacked. }\end{array}$ \\
\hline 1007 & One Hacker & $\begin{array}{l}\text { 1 second record consisting of one } \\
64 \text { second record correlated. }\end{array}$ \\
\hline 1009 and 1010 & Two Hackers & $\begin{array}{l}\text { 1 second record consisting of one } \\
64 \text { second record correlated. }\end{array}$ \\
\hline 1020 & One Hacker & $\begin{array}{l}\text { 1 second record consisting of } \\
\text { stack of 16 hits using a hammer } \\
\text { trigger and recorded in stacking } \\
\text { mode, emulating the hammer } \\
\text { method. }\end{array}$ \\
\hline & & \\
\hline
\end{tabular}

\section{DisCuSSION AND CONCLUSIONS}

Amplitude and frequency analysis indicate that the timber is generally superior to the steel Swave cleat. Amplitudes of the first-arrival refraction phases at about $220 \mathrm{~ms}$ travel time for the sledgehammer-timber arrangement on the farthest offset traces are 3 to 6 times greater than for the steel cleat. This amplitude difference is seen when comparing seismic records from the two sources that are scaled to show their true relative amplitudes (Figure 4). More of the induced energy is transmitted the full distance of the receiver line when using the timber. This is an expected result as it is possible to strike the timber with greater force than is possible using the steel shoe. All seismic sources produced the expected clear first arrivals, followed by, predominantly, surface waves. The primary difference in these two configurations is simply a factor of power induced by striking the timber more forcefully than the shoe. The dominant frequency peak of the hammer-timber source at about $45 \mathrm{~Hz}$ is also about $10 \mathrm{~Hz}$ higher than the steel cleat (Figure 5a and 5b). For deposits with 
an S-wave velocity of $200 \mathrm{~m} / \mathrm{s}$, this higher frequency peak would allow about $0.4 \mathrm{~m}$ improvement in resolving a thin bed for the hammer-timber source. Despite the lower amplitude and dominant frequency of the steel cleat, we have found this source to be invaluable when space constraints preclude the use of a vehicle parked on the timber. For future comparisons against the Hacker source described below, the sledgehammer-timber record (file 1004) is considered as the control record.

To isolate the differences between a single Hacker impact and four hammer impacts against a timber recorded at this site we compared individual sample amplitudes and whole-record frequency analysis. At the time of this writing, we do not have a single hammer impact record to compare against the single Hacker blow at this site. For the first-arrival phases, the hammer-timber record shows about 1.5 times higher amplitudes at the midpoint of the receiver spread, which suggests that an individual Hacker impact is roughly equivalent to or slightly more energetic than a single hammer impact (Figure 6). These two seismic sources also have a similar dominant frequency peak at about $45 \mathrm{~Hz}$ (Figure 5).

Next, we compared the sledgehammer-timber record (1004) with two different correlated Hacker source input-time variations (records 1006 and 1007, Fig. 7; also see Table 1). We recorded these data using a single Hacker and found, as expected from our experience using tampers in a vertical mode, that a single tamper does not provide a sufficiently random series of impulses and results in the appearance of multiple first arrivals or correlation noise (Figure 7). Correlation noise appears as a "ghosting" arrival that occurs before time zero, and/or later in the record as repetitive first arrivals at regular intervals. In this test, however, a single Hacker also produced strong first arrivals that, although somewhat obscured by correlation noise, appear to be more continuous, of higher amplitude, and with less interference from ambient high-frequency wind noise than the hammer-timber source (Figure 7). Because the true amplitudes of the Hacker data are lost during the correlation process, amplitude comparisons between the hammer-timber and the Hacker are not possible. However, given the relatively equal amplitudes of individual Hacker impacts and the hammer-timber source as described above, signal-to-noise improvements for the 60-s Hacker record should be about a factor of 13 for 175 source stacks. It does not appear that 64-s single recording has any advantage over a stack of 4, 24-s recordings for a receiver array of this length at this site (Figure 7). Whether or not to record a single long record as opposed to a group of shorter records is 
usually site dependent. The ambient noise conditions at some sites may require the use of shorter records to avoid some of the noise.

Record 1009 (Figure 8) was made using two horizontal tampers in an effort to reduce correlation noise and to improve the signal-to-noise ratio by increasing the number of source inputs without increasing total source input time. Comparing the two-Hacker record (1009) to the control record (1004), we find the first arrivals are strong and clear for the full distance of the receiver spread, indicating that it is feasible to increase the number of active channels or extend the distance of the existing channels. However, it does not appear that correlation noise is reduced by using two Hackers instead of one.

Record 1020 was made using a single Hacker without the correlation process to emulate a sledgehammer record (Figure 9). The seismograph was configured for stacking individual blows rather than correlation of the Hacker impact time series with the data, and a commercial hammer switch was used as the impact sensing device. The tamper was run up to full operating speed, then rolled forward on the wheels to contact the timber for one hit, allowed to recoil backward, and repeated to accumulate a stack of sixteen hits. This record most closely replicates the sledgehammer record.

If the correlation noise problem can be eliminated or highly reduced, then these results indicate that the Hacker is a practical alternative to the sledgehammer for the increased energy input, improvement of signal/noise ratio, speed of operation, portability, and reduction in human physical force requirements. It is recognized that additional testing at various sites is required for complete evaluation and that some adjustments in technique are required to provide the quality and integrity of data that has been achieved in P-wave data collection.

The only observed mechanical limitation to this technique is the apparent tendency of the tampers to induce undesirable energy into the ground upon recoil of the tamping mechanism. The next phase of testing includes a restraint system to dampen the recoil and reduce this undesirable component of energy.

\section{ACKNOWLEDGMENTS}

This study was supported by funding from the National Earthquake Hazard Reduction Program (NEHRP). The authors thank the City of Golden, CO, Department of Parks and Recreation, for permission to use their land to conduct these tests. Use of commercial product names does not imply endorsement by the U.S. Geological Survey. 


\section{REFERENCES}

Barbier, M. G., 1983, The Mini-Sosie method: International Human Resources Development Corp., Boston, Mass., $186 \mathrm{p}$.

Kobayashi, N., 1959, A method of determining the underground structure by means of SH waves, Zisin, V.12, p. 12-24.

Liu, H.P., Warrick, R.E., Westerlund, R.E., Fletcher, J.B., and Maxwell, G.L., 1988, An air-powered impulsive shear-wave source with repeatable signals, Seismological Society of America, v. 78, p. 355369.

Meissner, R., Stümpel, H., and Theilen, F., 1985, Shear wave studies in shallow sediments (chap. 5), in Seismic Shear Waves, Part B: Applications, G. Dohr, Editor, Geophysical Press, London, England.

Scott, G. R., 1972, Geologic map of the Morrison quadrangle, Jefferson County, Colorado: U.S. Geological Survey Map I-790-A, 1:24000.

Stephenson, W.L., Odum, J.K., Williams, R.A., Pratt, T.L., Harrison, R.W., and D. Hoffman, 1999, Quaternary faulting in southeast Missouri across the Commerce geophysical lineament: Bulletin Seismological Society of America, v. 89, p. 140-155. 


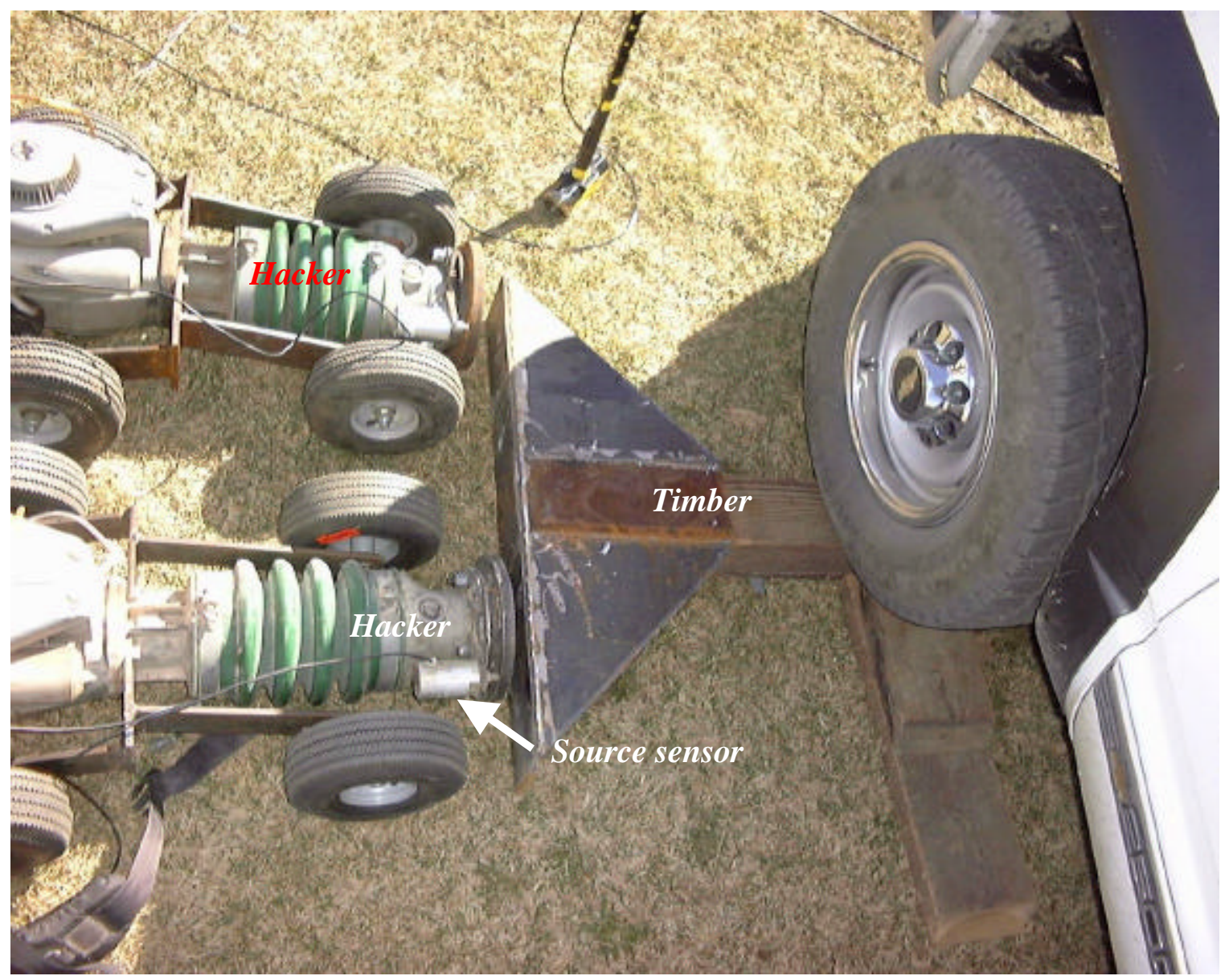

Figure 1-Horizontally configured tampers (Hackers) at field test location. 


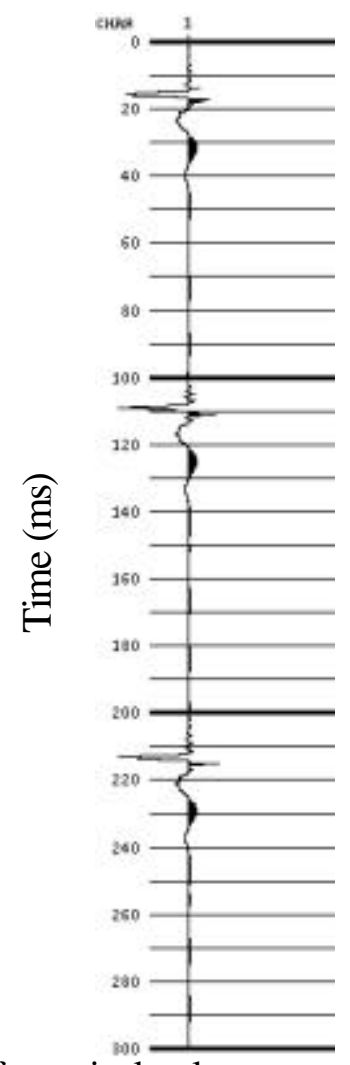

Figure 2. Three pulses from a portion of a typical pulse sequence generated by the impact-sensing device (labeled "Source sensor" in Figure 1) attached to the base of the Hacker. These pulses are recorded on channel 1 and then used to correlate with the data on channels 2 through 60.

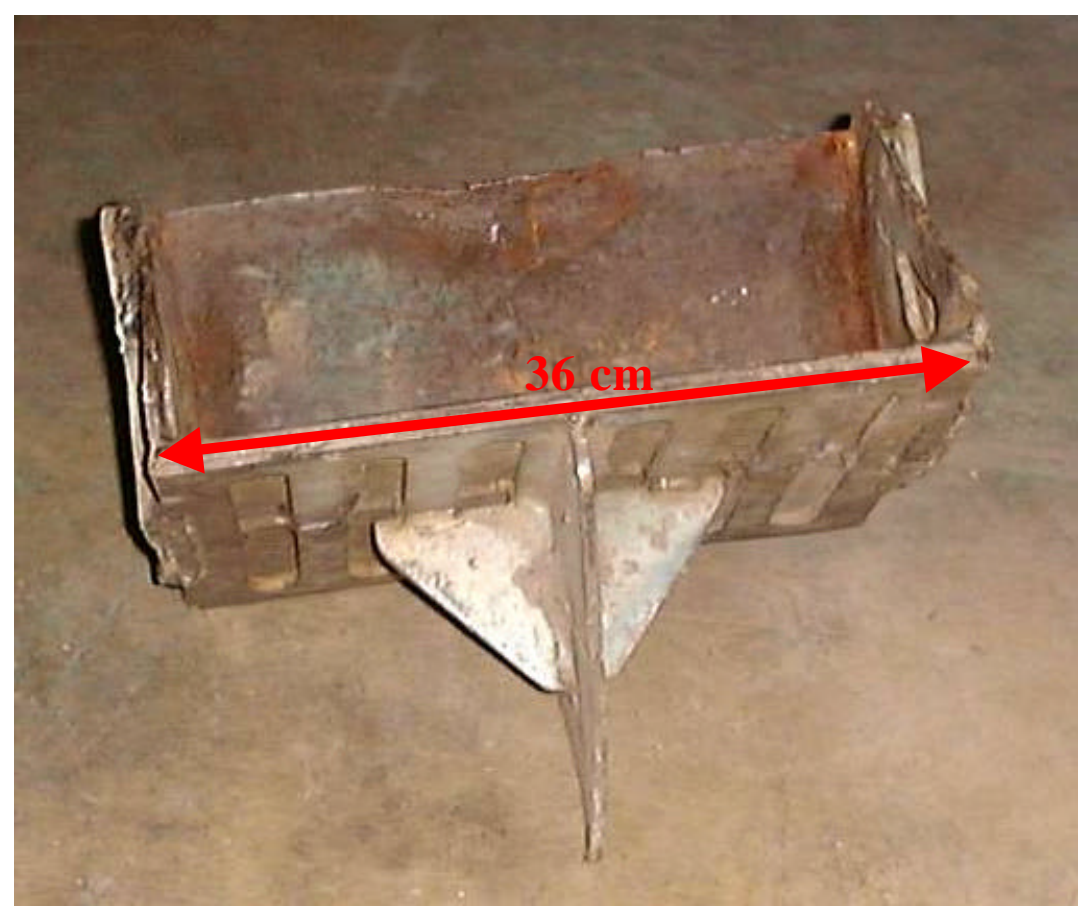

Figure 3. Underside of Steel cleat showing triangular points for penetrating soil to increase signal coupling. 


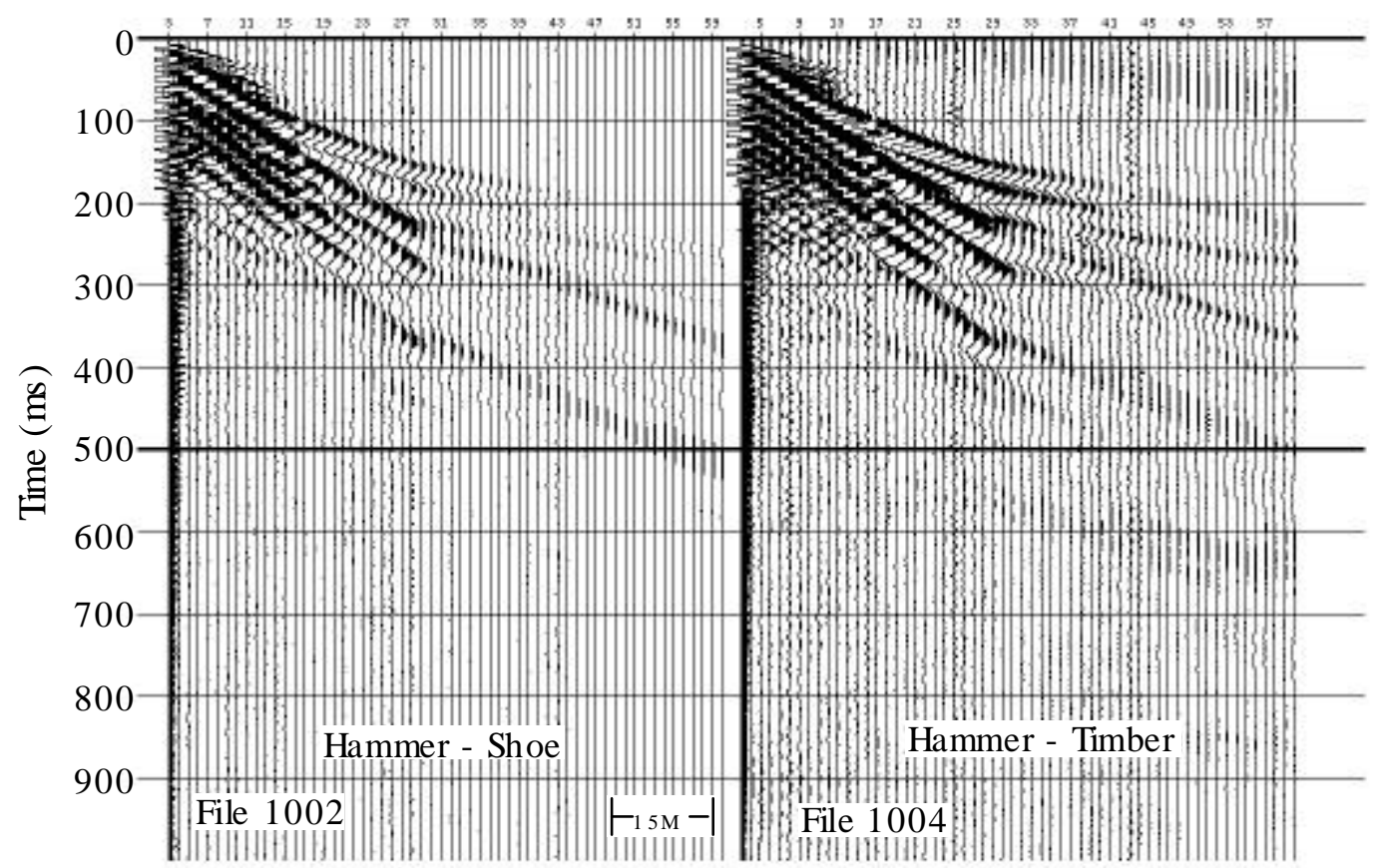

Figure 4. Compares hammer blows on steel shoe and timber. File 1004, on the right, is the control record for comparisons in this paper. 

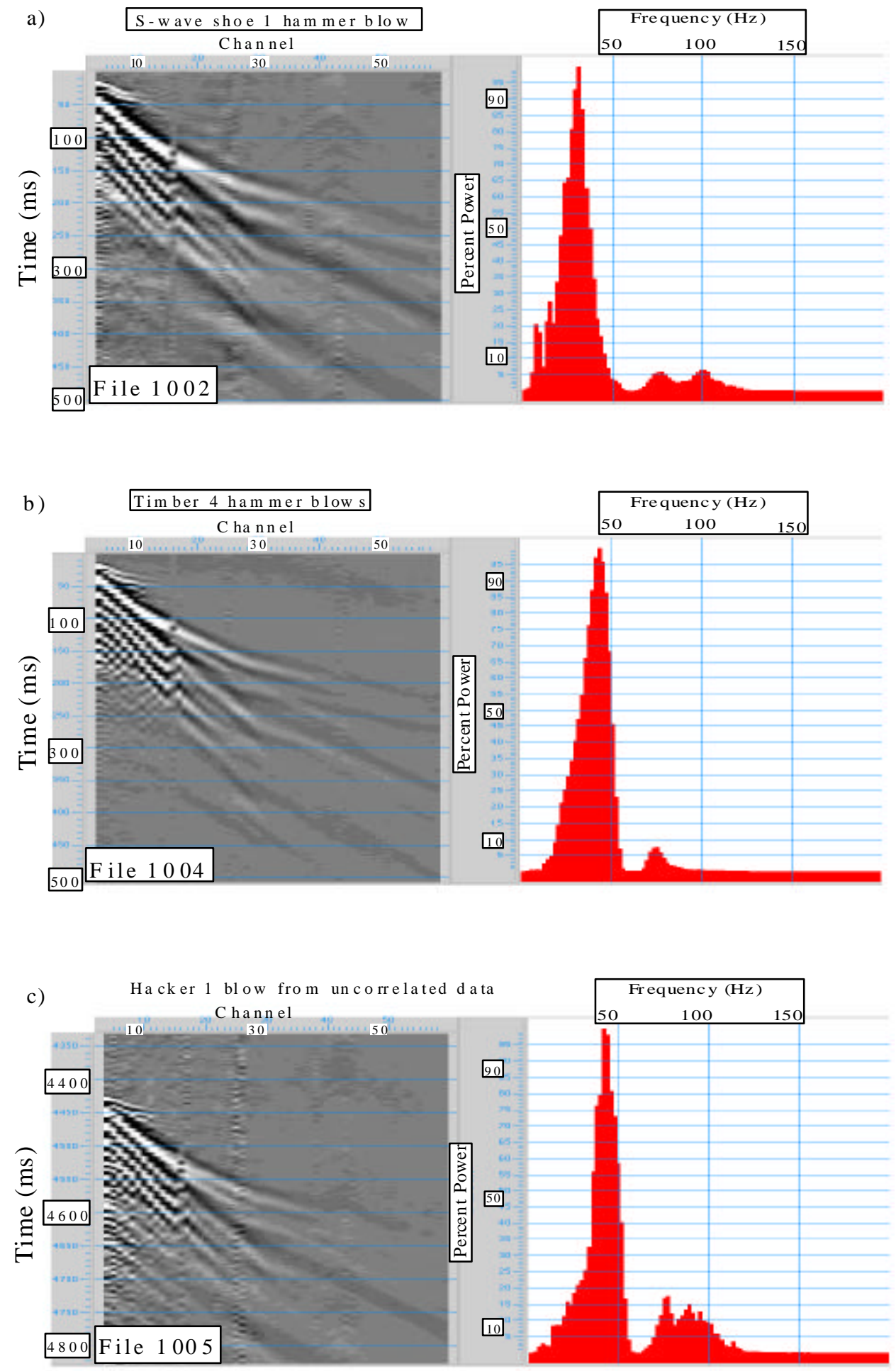

Figure 5. Spectral comparisons. Energy from the timber is nearer $50 \mathrm{~Hz}$. Energy from the shoe is nearer $25 \mathrm{~Hz}$. W ith the $\mathrm{Hacker}$, there is greater energy in the 75-100 Hz. range. 


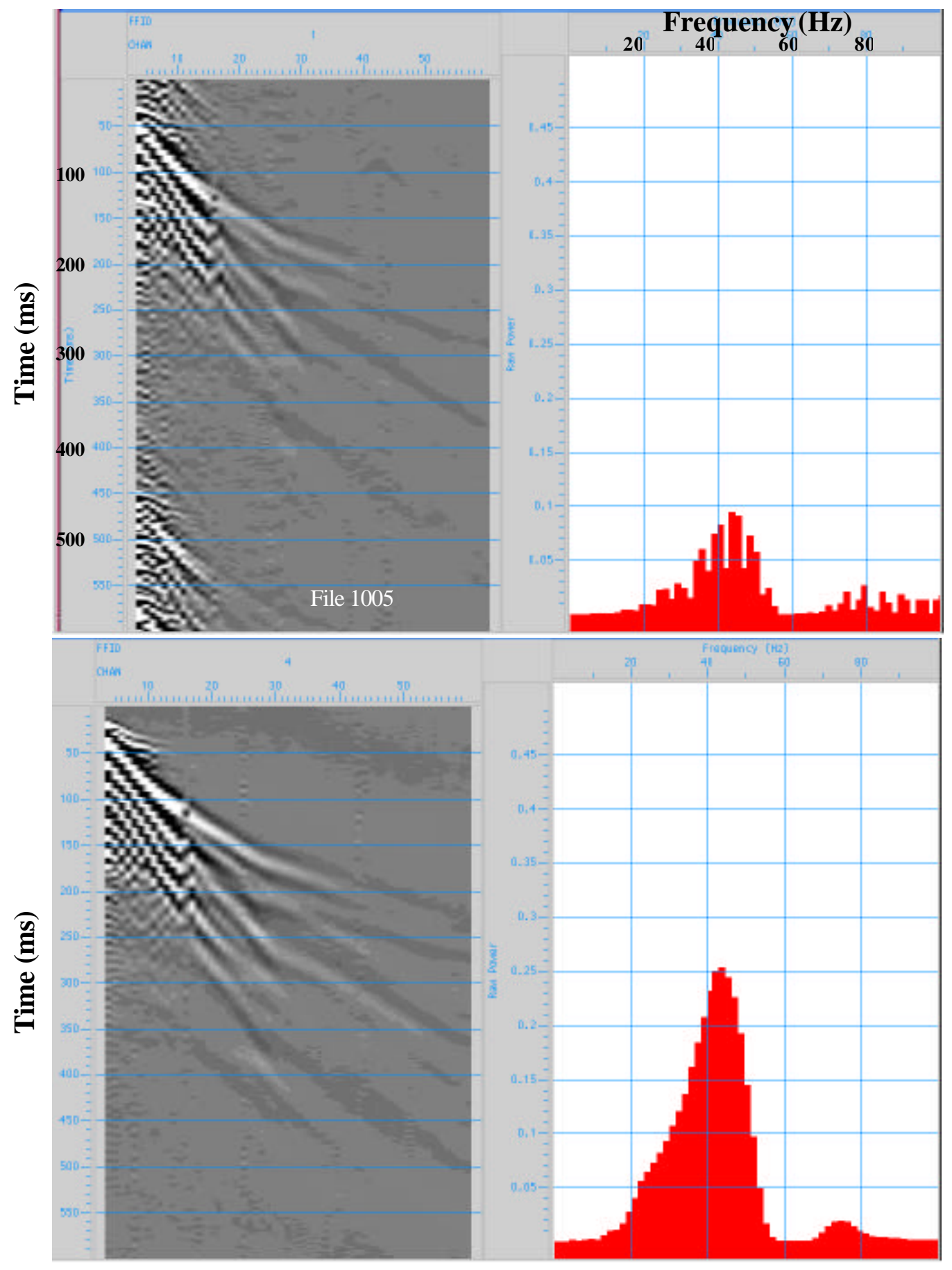

Figure 6. Relative amplitude and frequency comparison between a single, uncorrelated Hacker impact (top) and 4 stacks of the hammer-timber configuration (bottom). Frequency peaks are about the same for each source. Amplitudes are slightly greater for the 4-stack hammer record probably because of the stacking. 


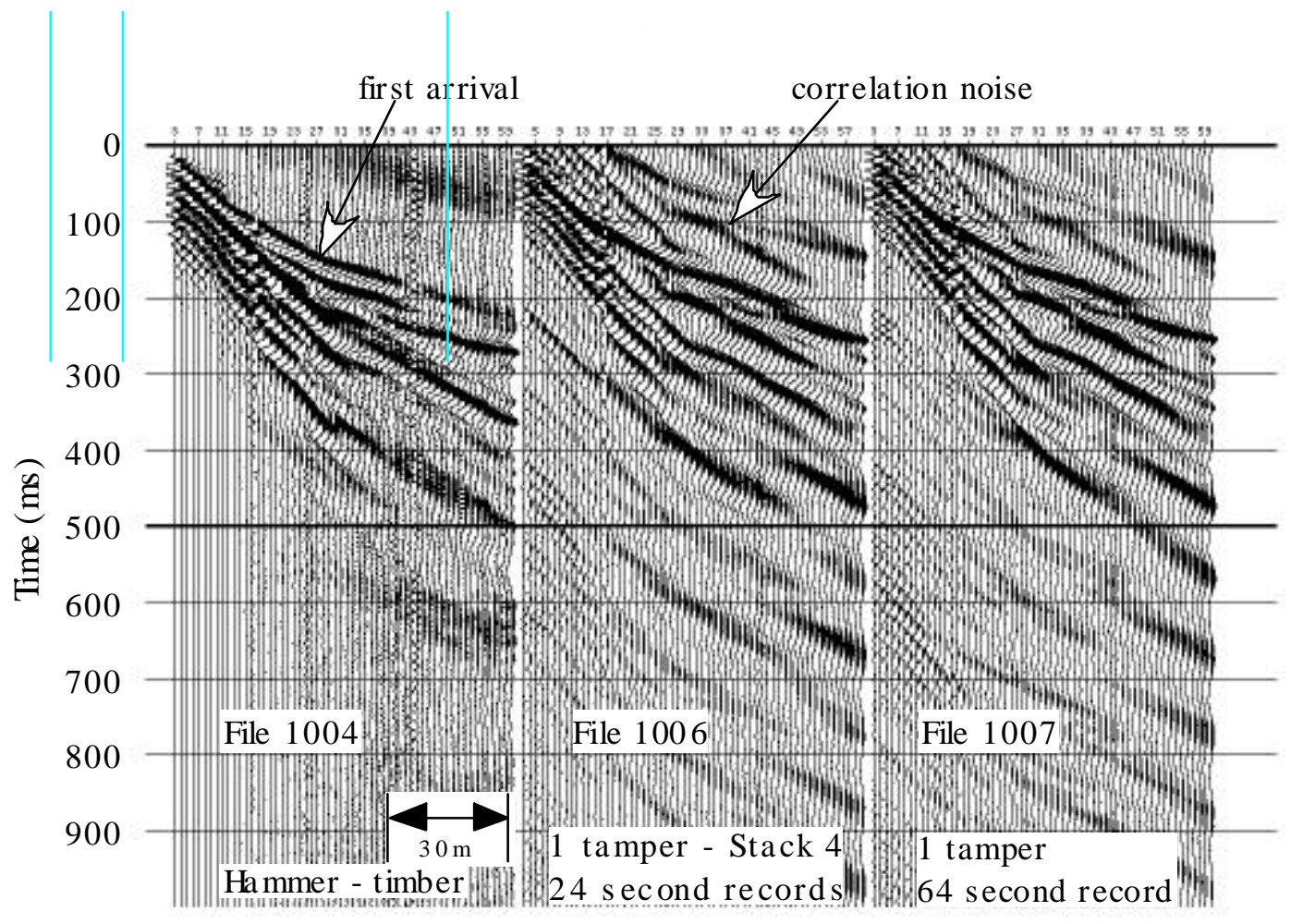

Figure 7. Records 1004, 1006, 1007. Comparing hammer to single Wacker in two different time configurations. Some correlation noise introduced by ins ufficient randomness of single tamper. 


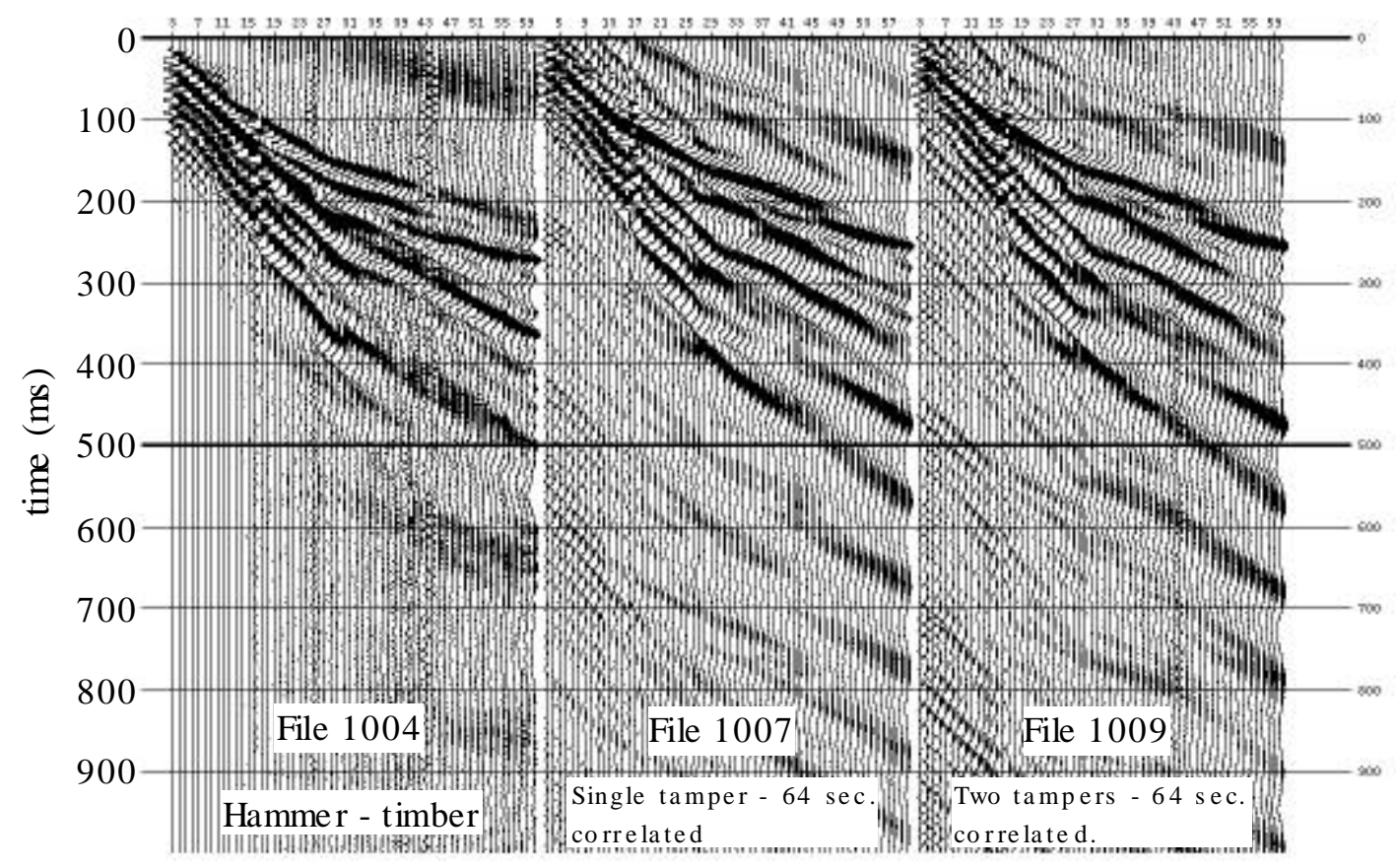

Figure 8. Files 1004, 1007, and 1009. The addition of a second tamper shows a slight improvement in data quality, but retains the induced correlation noise. 


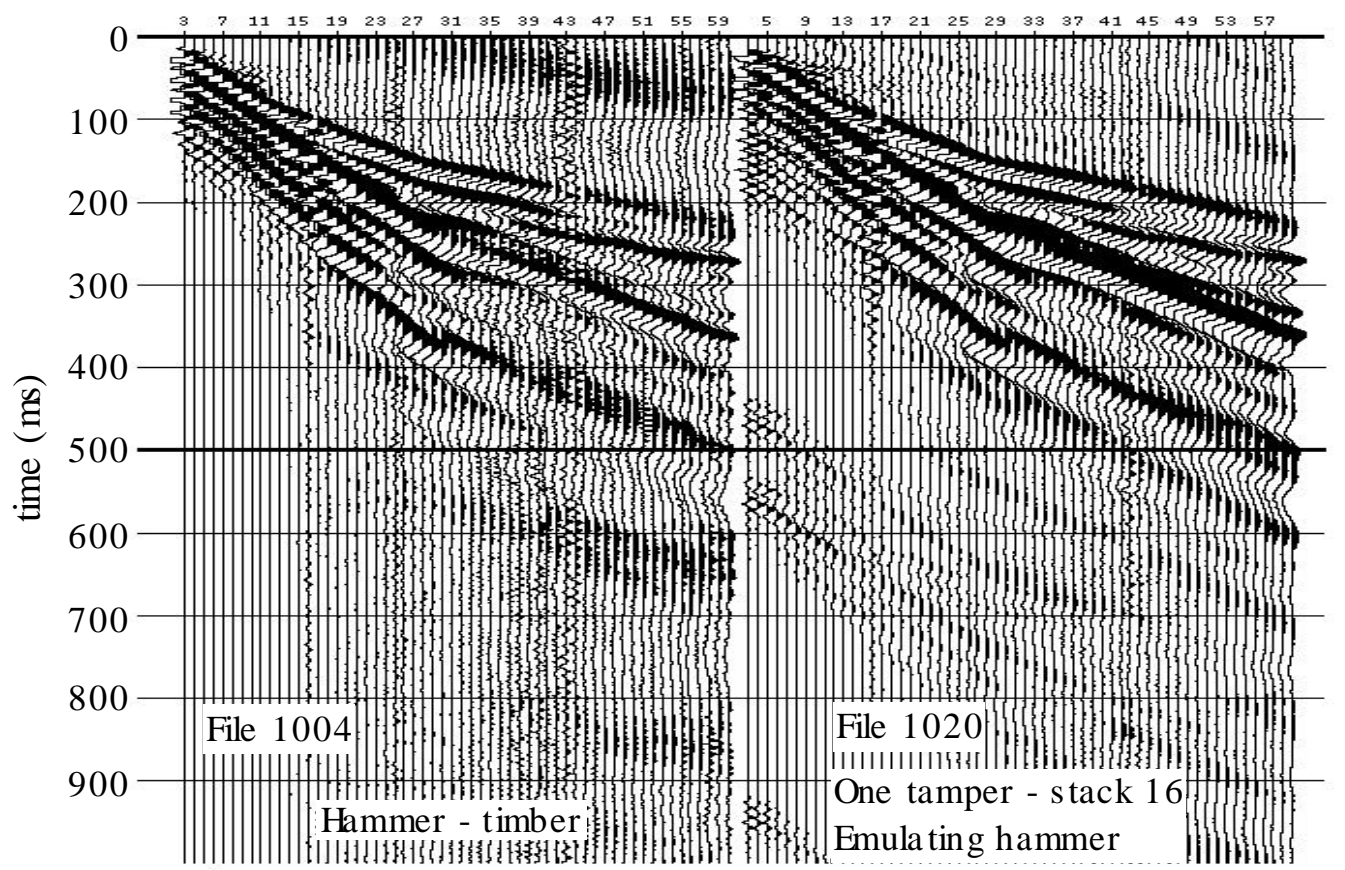

Figure 9. Files 1004 and 1020 . Comparing hammer blows to stacking tamper impacts. Improved $\mathrm{S} / \mathrm{N}$ ratio of tamper record improves appearance of data with no introduction of correlation noise. 